\title{
Ciclos político-eleitorais e alocação dos gastos públicos: uma análise para os municípios brasileiros
}

\author{
Political electoral cycles and public expenditure allocation: an analysis for \\ Brazilian municipalities
}

Fabiano Dal-Ri e Fernando Motta Correia ${ }^{*}$

\begin{abstract}
Resumo: O objetivo do artigo é analisar a evolução dos ciclos políticos nos municípios brasileiros com base em séries históricas de variáveis orçamentárias. Busca-se observar de que forma os municípios respondem à mudança regulatória trazida pela Lei de Responsabilidade Fiscal no manejo dos gastos públicos. Aplica-se uma base teórica desenvolvida desde a década de 70 a partir da Teoria dos Ciclos Orçamentários. Utilizamse dados fiscais disponibilizados por meio do Tesouro Nacional. Os principais resultados mostram um canal aberto para utilização de critérios discricionários na alocação dos recursos públicos, que adquirem caráter cíclico diante de interesses eleitorais. Tal situação se revela particularmente intensa nos municípios mais dependentes de transferências governamentais, indicando, mais uma vez, a utilização oportunista de recursos públicos na busca de resultados políticos.
\end{abstract}

Palavras-chave: Gastos públicos; Ciclos orçamentários; Municípios brasileiros

\begin{abstract}
The aim of this paper is to understand the political cycles in Brazilian municipalities based on historical series of budget variables. It is observed how the municipalities react to the regulatory change brought by the Fiscal Responsibility Law in the management of public spending. It is applied a theoretical basis developed since the 70 's from the Budget Cycle Theory. Additionally, it is used tax data provided by the Brazilian National Treasury. The main results show an open channel for the use of discretionary criteria in the allocation of public resources, which become cyclical in the face of electoral interests. This situation is particularly intense in municipalities more dependent on government transfers, indicating once again the opportunistic use of public resources in the pursuit of political results.
\end{abstract}

Keywords: Public spending; Budget cycles; Brazilian municipalities

JEL: H76; H72; H79

\footnotetext{
* Respectivamente, doutorando em Economia dos Negócios/Insper. Graduado em Ciências Econômicas/UFPR. E-mail: dalri.fabiano@gmail.com. Orcid: https://orcid.org/0000-0002-0904-5251; e doutor em Desenvolvimento Econômico/UFPR. Professor do Departamento de Economia da UFPR. Email: fmottabr@yahoo.com.br. Orcid: https://orcid.org/0000-0002-0739-6103.
} 


\section{Introdução}

A relação entre política e economia é - e sempre foi - um tema controverso que suscita as mais variáveis discussões. Ao menos desde o século XVIII, quando a ciência econômica surge de forma mais metódica e estruturada a partir dos textos de Adam Smith, a busca por determinar de que forma se dá tal interação tem ocupado diferentes papéis em análises de diversas correntes. Se a ciência inaugurada pelo texto Uma Investigação sobre a Natureza e as Causas da Riqueza das Nações era então chamada de economia política justamente por colocar em evidência a complementaridade entre economia e política, os desenvolvimentos teóricos subsequentes acabaram por mudar de rumo. Dentro da tradição neoclássica, por exemplo, a motivação política na tomada de decisões econômicas é frequentemente desconsiderada (FIALHO, 1999).

Negligenciar a variável política em análises econômicas e financeiras é, no entanto, incabível para momentos como aquele pelo qual o Brasil passa em pleno século XXI. O impacto de uma crise política aguda como a atual tem se refletido diretamente em aspectos econômicos que acabaram por colocar o país em meio a uma das mais severas recessões de sua história. A redução da atividade econômica tem afetado não apenas o setor privado, mas também os entes federativos, cujas contas são colocadas à prova diante de uma intensa e inesperada restrição orçamentária. Essa simbiose entre ciclos políticos, econômicos e orçamentários que se revela com força máxima na conjuntura presente é campo prolífico para estudos, numa sequência de avanços teóricos e metodológicos que têm como marco inicial o texto de William D. Nordhaus na década de 70. Desde então, a questão que começou com a análise da relação entre ciclos políticos e movimentações em variáveis macroeconômicas a partir de canais monetários de transmissão passou a indicar que há, ainda, uma interação entre ciclos políticos e utilização de instrumentos fiscais que se reflete nos orçamentos públicos e que possui fortes repercussões principalmente sobre os municípios.

É justamente a interação entre ciclos políticos e orçamentários nos municípios brasileiros que este artigo pretende avaliar, procurando identificar de que forma uma mudança institucional como aquela provocada pela promulgação da chamada Lei de Responsabilidade Fiscal (LRF) altera os incentivos na gestão das finanças públicas. O objetivo, portanto, é analisar a variação dos ciclos políticos utilizando séries históricas de variáveis orçamentárias municipais e 
observar de que forma elas respondem a mudanças regulatórias no manejo da coisa pública. Pretende-se, ainda, elencar diferenças no comportamento dos municípios de acordo com a faixa populacional e a região geográfica em que se encontram. A hipótese adotada é a de que a LRF, apesar de impor limites máximos de gastos com pessoal e de endividamento, não adotou critérios que guiassem os gastos com investimentos, deixando aberto um canal passível de ser utilizado ciclicamente por políticos de forma oportunista visando maximizar o resultado eleitoral.

De forma a validar a hipótese acima indicada, o artigo está estruturado da seguinte forma: a segunda seção (sendo a primeira esta introdução) traz uma revisão dos desenvolvimentos teóricos e institucionais relevantes para a discussão de ciclos político-orçamentários municipais; a terceira apresenta uma análise das despesas com pessoal e investimento nos municípios brasileiros; a quarta revela os resultados encontrados a partir da análise dos indicadores selecionados; e a quinta abre espaço para as considerações finais.

\section{Revisão de literatura}

Ciclos político eleitorais, também chamados de ciclos político-econômicos ou, numa perspectiva mais recente, de ciclos político-orçamentários, buscam examinar a relação entre decisões de caráter político e econômico que interagem de forma cíclica. Nessa perspectiva, as decisões políticas passam a ter relevância no entendimento de fenômenos econômicos e a assumir um caráter endógeno ao sistema, condicionando e sendo condicionadas pela realidade econômica. Por isso, analisar tal interação é fundamental para que se evitem "diagnósticos [macroeconômicos] equivocados que implicam, por sua vez, em imprecisões e erros nas previsões da trajetória futura dos eventos econômicos, em geral, com consequências negativas sobre o bem-estar da sociedade" (FIALHO, 1999, p. 132). Ainda assim, a teoria econômica frequentemente ignora a motivação política (o que inclui interesses privados e objetivos político-eleitorais) que há por trás da tomada de decisões governamentais, algo que diversos autores vêm tentando contornar nas últimas décadas.

Apesar de a teoria de ciclos político-eleitorais ganhar maior notoriedade a partir da década de 70 com a formulação teórica de Nordhaus, conforme será mostrado adiante, ideias pontuais acerca do impacto que decisões políticas podem ter sobre o desempenho econômico datam de um período anterior. Fialho (1999) 
aponta que Kalecki, por exemplo, em sua obra Os Aspectos Políticos do Pleno Emprego de 1943, já previa que ciclos econômicos causados por motivos políticos seriam sistemáticos em um sistema democrático capitalista no qual os candidatos tentam ganhar votos do eleitorado e os influenciar. A ideia de Kalecki é, então, melhor desenvolvida por Downs no texto An Economic Theory of Democracy de 1957, que mostra que partidos políticos agem racionalmente ao tentar maximizar o desempenho eleitoral, formulando políticas que gerem votos ainda que com impactos econômicos diversos. Nessa visão, os efeitos econômicos seriam relevantes apenas se influenciassem o eleitorado, o qual toma sua decisão com base no desempenho passado. Key Jr, na sequência, publica o texto The Responsable Electorate de 1966, em que, apesar de concordar com a importância da política sobre ciclos eleitorais, defende que é o desempenho econômico recente (e não o passado) que mais influencia o voto eleitoral.

No artigo The Political Business Cycle publicado em 1975, William D. Nordhaus procura desenvolver uma abordagem que supere a falta de teoria econômica acerca do comportamento governamental diante de limitações políticas, aprofundando, portanto, as ideias de autores como Kalecki, Downs e Key Jr, citados anteriormente. Para tanto, Nordhaus parte de um modelo intertemporal com um trade-off entre inflação e desemprego (tal qual na curva de Phillips), em que os eleitores são sensíveis a ambas as variáveis - ao desemprego, porque, direta ou indiretamente, a renda de muitas famílias é comprometida; à inflação, porque ela torna a alocação de recursos menos eficiente, gera efeitos redistributivos e pode causar problemas de pagamentos. As famílias, no entanto, não conhecem o tradeoff econômico, apesar de terem suas preferências definidas. Como o próprio Nordhaus (1975) coloca, "voters don't know much about economics but they know what they like" (p. 173). ${ }^{1}$

Uma situação similar ocorre em relação às preferências partidárias: para Nordhaus, fatores ideológicos partidários são menos importantes do que o histórico do partido em relação à inflação e ao desemprego. Isso porque os eleitores usam experiências passadas aliadas à situação presente na tomada de decisão. Pode-se afirmar que, nessa visão, os eleitores formam expectativas acerca do comportamento dos partidos e o desempenho deles é avaliado em relação a essas

\footnotetext{
1 “Eleitores não sabem muito sobre economia, mas eles sabem do que gostam.” Tradução nossa.
} 
expectativas. Assume-se, ainda, que os partidos possuem o único objetivo de ganhar votos e, consequentemente, eleições. Assim, as decisões econômicas tomadas ao longo de um mandato buscam maximizar o resultado nas próximas eleições, sendo necessário, para tanto, conquistar uma pluralidade de eleitores. É com esse objetivo que os políticos manipulam resultados econômicos de forma que eles estejam em seu melhor estado justamente na época de eleições.

A lógica do modelo de Nordhaus está em perceber que combinações de menor desemprego e menor inflação geram resultados eleitorais mais positivos. Logo, no curto prazo, busca-se alcançar dentro da curva de Phillips um resultado que maximize o resultado eleitoral. Esse ponto, no entanto, não é o ponto ótimo de longo prazo, pois Nordhaus identifica que, em sociedades democráticas, há uma tendência a se privilegiar o bem-estar presente em relação ao bem-estar futuro. $O$ longo prazo, de qualquer forma, encontra-se fora do alcance de manipulações políticas, indicando que manipulações de curto prazo terão de ser revertidas após as eleições, gerando os ciclos políticos.

Uma importante revelação do modelo de Nordhaus é a de que é a própria natureza democrática que leva ao surgimento dos ciclos, os quais derivam de uma situação em que os políticos procuram agradar o eleitorado de forma a se (re)elegerem, indicando a existência de oportunismo eleitoral. Assim, um ciclo típico assumiria a seguinte forma:

Immediately after an election the victor will raise unemployment to some relatively high level in order to combat inflation. As elections approach, the unemployment rate will be lowered until, on election eve, the unemployment rate will be lowered to the purely myopic level ${ }^{2}$. (NORDHAUS, 1975, p. 184). ${ }^{3}$

As manipulações da atividade econômica se dão, no modelo de Nordhaus, por meio de política monetária. Uma política expansionista, por exemplo, levaria a um aumento da atividade econômica e, após um período de resposta, a um

\footnotetext{
${ }^{2} \mathrm{O}$ nível de miopia é aquele em que gerações futuras são ignoradas e, portanto, se busca uma baixa taxa de desemprego ainda que isso resulte em uma inflação mais elevada. Esse nível se contrasta com o nível de solução política golden-rule, no qual não há diferenciação entre gerações, e o nível de bem-estar ótimo, em que ambas as gerações são consideradas.

3 "Imediatamente após uma eleição o vencedor irá aumentar o desemprego para algum nível relativamente elevado de forma a combater a inflação. Conforme as eleições se aproximem, a taxa de desemprego será diminuída até que, às vésperas da eleição, a taxa de desemprego será diminuída para o nível de miopia pura". Tradução nossa.
} 
aumento de inflação (DRAZEN, 2001), de tal forma que as mudanças ao longo da curva de Phillips assumem papel central nesse modelo teórico.

Para sustentar sua teoria, Nordhaus analisa alguns países desenvolvidos (Austrália, Canadá, França, Alemanha, Japão, Nova Zelândia, Suécia, Reino Unido e Estados Unidos). A hipótese de existência de ciclos é rejeitada no caso da Austrália, do Canadá, do Japão e do Reino Unido, mas há pequena evidência na França e Alemanha, além de ciclos mais significativos na Alemanha, na Nova Zelândia e nos Estados Unidos. Fialho (1999, p. 134) critica os resultados encontrados originalmente por Nordhaus e considera que "a evidência empírica por ele apresentada (...) parece não suportar muito bem a ideia de um ciclo político".

O modelo teórico de Nordhaus, conforme se observou anteriormente, apoiava-se nas expectativas adaptativas, indicando que os eleitores formavam suas análises do momento político e econômico levando em consideração somente o passado e o presente, com pequeno conhecimento da teoria econômica e de relações como o trade-off entre inflação e desemprego contido na curva de Phillips. Essa mesma perspectiva se manteve em estudos posteriores, como os de Hibbs em 1977 e 1987 - que incluíram a teoria partidária buscando compreender a influência da dimensão ideológica partidária sobre os ciclos - e o de Beck em 1982 - que, por sua vez, aponta que as composições partidárias se alteram no tempo e, portanto, é difícil traçar um perfil dos partidos que se mantenha. Beck, de certa forma, refuta os achados de Hibbs a respeito da importância de considerações partidárias (FIALHO, 1999).

As principais críticas em relação aos modelos até aqui citados se concentram, de acordo com Drazen (2001), em três pontos principais: na suposição de que o poder executivo controla a política monetária, algo que é limitado (ou mesmo pouco plausível) dentro de uma estrutura institucional na qual os Bancos Centrais gozam de uma mínima independência; na centralidade da política monetária, ignorando aspectos importantes da política fiscal que também podem influenciar ciclicamente o desempenho econômico de um país; e na suposição de que os eleitores são irracionais. Caso eles sejam racionais, as decisões seriam tomadas com base não no comportamento passado dos candidatos, mas na expectativa de desempenho futuro deles, além de haver menor resposta a manipulações, uma vez que os interesses por trás de tais medidas seriam antecipados. Assim, os desenvolvimentos teóricos posteriores buscam superar o 
que se via como limitações dos modelos tradicionais de ciclos político eleitorais. Alesina e Rogoff são dois dos principais autores que trilharão tal caminho, levando a teoria dos ciclos político-eleitorais a novos horizontes.

De modo a superar a suposição de que os eleitores são irracionais, apoia-se na revolução das expectativas racionais no final da década de 70 e anos 80 . Uma vez que um dos alicerces do modelo de Nordhaus é justamente a falta de conhecimento do sistema econômico por parte dos eleitores - o que impossibilita que eles antecipem as decisões dos policy markers -, assumir que eles são, na verdade, racionais e conhecem o sistema torna mais difícil justificar a existência de ciclos. Essa limitação do modelo é reconhecida pelo próprio Nordhaus, além de autores como Sargent e Wallace. Esses últimos, em texto também de 1975 (mesmo ano de publicação do texto seminal de Nordhaus), defendem que, caso se suponha racionalidade dos agentes, a exploração sistemática da curva de Phillips para gerar resultados econômicos favoráveis a reeleições não é possível (FIALHO, 1999).

Para conciliar a existência de ciclos políticos com as expectativas racionais, Alesina sugere, dentro de um modelo que considera diferenças ideológicas entre os partidos, que efeitos de políticas monetárias ativas sobre a atividade econômica só serão visíveis caso elas ocorram de surpresa. Nesse caso, partidos de esquerda tendem a seguir uma política mais inflacionária, enquanto que os de direita seguem o caminho contrário, de tal forma que a inflação esperada se mantém entre esses dois valores. Logo, "there is a positive inflation surprise if the left-wing party wins the election, implying unemployment below the natural rate, and a negative inflation surprise if the right-wing party wins the election, implying unemployment above the natural rate" (DRAZEN, 2001, p. 91). ${ }^{4}$ É por esse motivo que a existência de ciclos sob expectativas racionais depende da incerteza sobre resultados eleitorais.

Conforme aponta Fialho (1999), a diferença de resultados no modelo de Alesina entre partidos de posições opostas no espectro ideológico serve de incentivo para que sejam definidas regras comuns e normas políticas cooperativas. Assim, um aumento de interação entre os diferentes partidos reduz a magnitude

\footnotetext{
4 "Há uma surpresa inflacionária positiva se o partido de esquerda ganha a eleição, implicando em desemprego abaixo da taxa natural, e uma surpresa inflacionária negativa se o partido de direita ganha a eleição, implicando em taxa de desemprego acima da taxa natural". Tradução nossa.
} 
das flutuações econômicas, uma vez que são diminuídos os espaços de manobra para manipulações eleitorais.

Se Alesina incluiu com sucesso as expectativas racionais nos modelos de ciclos políticos, coube a Rogoff, no final da década de 80 , os principais avanços ${ }^{5}$ em relação à mudança de foco da política monetária para a política fiscal, superando, portanto, mais uma das críticas que se fazia ao modelo original de Nordhaus. Isso porque

A principal conclusion is that models based on manipulating the economy via monetary policy are unconvincing both theoretically and empirically, while explanations based on fiscal policy conform much better to the data and form a stronger basis for a convincing theoretical model of electoral effects on economic outcomes. (DRAZEN, 2001, p. 77) ${ }^{6}$

Conforme aponta Fialho (1999), Rogoff consegue aproveitar um contexto de expectativas racionais para desenvolver sua análise de ciclos a partir de variáveis fiscais. Para tanto, é levado em conta que há assimetrias de informações: geralmente, os eleitores possuem informações falhas e incompletas a respeito dos governantes. Essa situação pode propiciar o surgimento de ciclos, que ocorrem dentro de um modelo de seleção adversa. Rogoff aponta que os eleitores querem eleger candidatos competentes e que tal competência é avaliada por meio da capacidade de implementar políticas fiscais. Uma vez que essa avaliação é prejudicada pela assimetria de informações comentada anteriormente (apenas o próprio candidato conhece o seu nível de competência), um candidato competente buscará - e conseguirá - manipular o orçamento para incorrer em déficit no ano eleitoral e gastar com rubricas que chamem a atenção do eleitorado. Outra forma, caso não seja possível incorrer em déficits, é focar na mudança de alocação de gastos (mantendo-os iguais no agregado) e priorizar investimentos que sejam mais visíveis e bem avaliados pela população. O objetivo, nos dois casos, é justamente sinalizar o nível de competência e fazer isso a um baixo custo, algo de que um

\footnotetext{
${ }^{5}$ Fialho (1999) mostra que Tufte, por exemplo, foi um autor que, ainda na década de 70, focou na política fiscal como instrumento de manipulação eleitoral, ainda que de forma menos minuciosa e abrangente que Rogoff, além de não incluir uma perspectiva de expectativas racionais.

6 "Uma conclusão principal é que modelos baseados em manipular a economia através de política monetária não são convincentes teoricamente nem empiricamente, enquanto explicações baseadas em política fiscal se conformam muito melhor aos dados e formam uma base mais forte para um modelo teórico convincente dos efeitos eleitorais em resultados econômicos". Tradução nossa.
} 
candidato pouco competente não é capaz. Assim, a sinalização de competência é o que moveria a existência de ciclos (SHI; SVENSSON, 2003).

Vale ressaltar aqui que os impactos da utilização de instrumentos fiscais para sinalizar competência podem não se refletir em indicadores macroeconômicos como inflação, PIB e desemprego. Logo, os ciclos aparentam ser mais visíveis na forma de atuação dos governos do que nas consequências dessa atuação. (FIALHO, 1999). Além disso, Drazen e Eslava (2005) apontam que os efeitos de ciclos orçamentários são mais visíveis no nível local, pois os gastos podem ser melhor direcionados para atingir eleitores específicos. Essa mesma conclusão é alcançada por Veiga e Veiga (2007), que apontam que gastos típicos ao nível de governo nacional (como em defesa, relações exteriores, instituições legais etc.) são difíceis de serem avaliados pelo público e, por isso, ciclos orçamentários parecem ser mais aplicáveis a cenários locais. Os autores citam, ainda, o próprio Rogoff, que já havia indicado em texto de 1990 que a observação de dados estaduais e locais poderia ser frutífera.

Paralelamente aos desenvolvimentos já citados, houve ramificações da teoria de ciclos político-eleitorais que levaram a diferentes análises. Apesar de uma reflexão mais detalhada delas fugir ao escopo deste trabalho, cabe indicá-los a título de melhor compreensão histórica.

Um primeiro modelo alternativo ao de Rogoff foi proposto por Shi e Svensson (2003). Esses autores avançaram no tema ao mostrar que, além de os eleitores não saberem o nível de competência dos candidatos, os próprios candidatos não o sabem. Portanto, há um nível de incerteza a respeito do desempenho que os políticos terão ao longo do mandato. Isso os leva a alterar os níveis e a alocação de gastos, tal qual no modelo de seleção adversa. A diferença é que, aqui, tanto candidatos competentes quanto incompetentes irão fazer um esforço excessivo, de tal forma que os custos pós-eleitorais serão elevados para ambos os tipos de políticos.

Outro desenvolvimento a partir de Rogoff se dá em modelo proposto por Drazen (2001). Chamada de active-fiscal, passive-monetary (AFPM), essa teoria procura conciliar ciclos fiscais com ciclos monetários ao mostrar que, ao tentar sinalizar competência, um governante incorrerá em maiores gastos fiscais que terão de ser acomodados por uma política monetária restritiva. Dessa forma, seriam observados ciclos tanto em instrumentos fiscais quanto em monetários, mas 
não no produto agregado. Vale apontar que esse modelo AFPM é válido apenas para o cenário nacional, uma vez que níveis inferiores de governo (como estados e municípios) não possuem atuação sobre a política monetária.

Desdobramento adicional ocorreu com a incorporação da análise da Teoria dos Jogos à discussão, principalmente ao longo da década de 80. A ideia era buscar compreender de que forma se dá a relação entre agentes econômicos e o governo, incluindo discussões relacionadas à assimetria de informações, competência e consistência temporal. Alesina, já citado anteriormente, é um autor que desenvolveu trabalhos nessa área. (FIALHO, 1999).

Meneguin e Bugarin (2001), por sua vez, revisam e defendem os trabalhos da corrente de controle eleitoral, na qual, ao contrário dos modelos oportunísticos vistos até agora, a possibilidade de reeleição funciona como forma de avaliação dos políticos pelo eleitorado, que pode decidir deixá-los ou não no governo por mais um mandato. Assim, seria possível, com a introdução de reeleições, um maior controle dos governantes, que se veriam obrigados a serem mais esforçados e responsáveis.

\section{Distribuição das despesas públicas municipais}

A partir da literatura exposta, percebe-se que a teoria de ciclos políticos se metamorfoseou, na verdade, em uma teoria de ciclos orçamentários com maior evidência empírica e de aplicabilidade principalmente a níveis locais, o que no Brasil corresponde ao nível municipal.

Os municípios brasileiros estão inseridos em um contexto institucional federativo com forte concentração de receitas no nível federal, apesar de as responsabilidades - que implicam em gastos - serem divididas entre os três entes. Assim, tem-se a base para um modelo cuja marca é a dependência dos municípios por recursos federais e com alta propensão ao desequilíbrio orçamentário devido ao descompasso entre receitas e despesas. É nesse contexto que a LRF foi instituída e se estabeleceram indicadores limitantes do gasto público com maior foco sobre restrições de dívida e de gastos com pessoal. De acordo com o Gráfico 1, em média, a razão entre despesas com pessoal e receita corrente líquida tende a convergir ao nível de 50\%, abaixo do limite prudencial de 54\%. 


\section{Gráfico 1 - Distribuição da Razão Despesa com Pessoal/RCL nos Municípios brasileiros (média 2002-2017)}

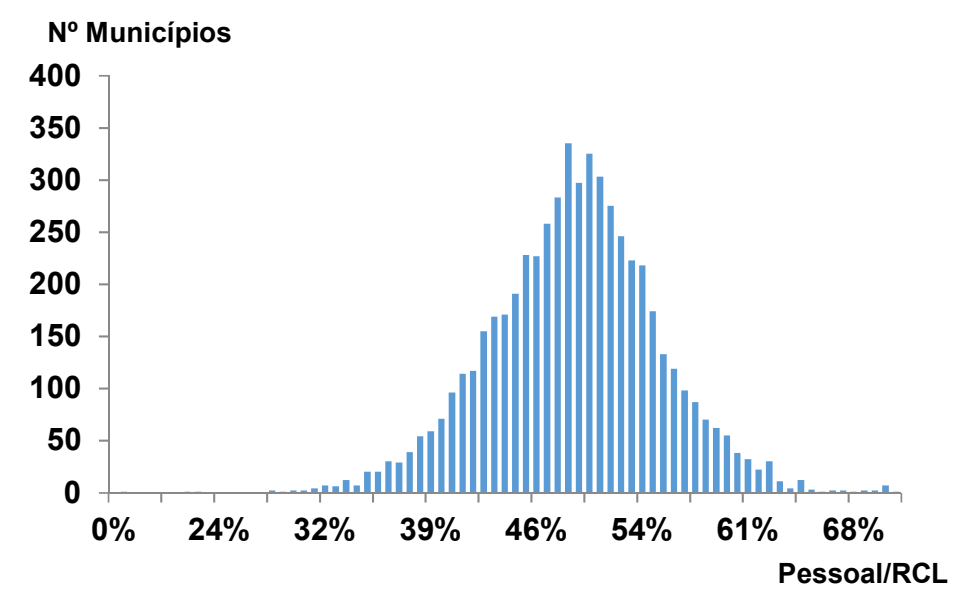

Fonte: Elaboração própria a partir dos dados do Tesouro Nacional.

Para as despesas com investimento, ao contrário, percebe-se que há uma heterogeneidade na distribuição dessas despesas de acordo com a Figura 1. Ainda que os gastos com investimentos sejam parcela significativa dos dispêndios governamentais, a LRF não estabeleceu limites para essas despesas, deixando-as livres da imposição direta de restrições

\section{Figura 1 - Distribuição da Razão Gastos Investimento/RCL nos Municípios brasileiros (média 2002-2017)}

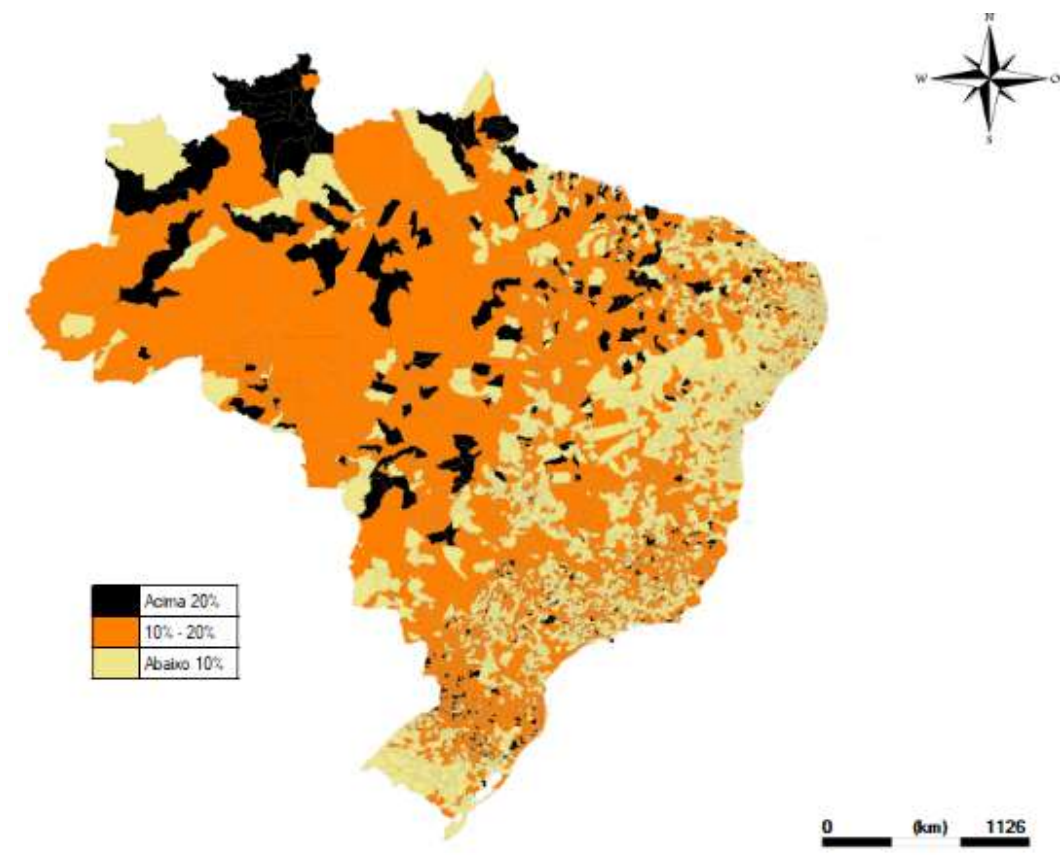

Fonte: Elaboração própria a partir dos dados do Tesouro Nacional. 
Ademais, de acordo com trabalhos de Klein e Sakurai (2014), Drazen e Eslava (2005), Sakurai e Menezes-Filho (2008) e Nakaguma e Bender (2005), sabese que gastos relacionados a investimento tendem a ser visíveis e aprovados pelos eleitores, de tal forma que sua manipulação traz resultados eleitorais positivos. A hipótese, portanto, é que o maior espaço de manobra com gastos de investimento aliado à visibilidade característica dessas despesas cria um cenário em que os investimentos adquirem um comportamento mais flexível e mais adaptável ao uso político e oportunista. Dessa forma, a observação de ciclos político-orçamentários se daria principalmente em indicadores relacionados a investimentos. É por essa razão que este trabalho procurará encontrar indícios de ciclos em um indicador síntese: a razão gastos com investimento por gastos com pessoal. ${ }^{7}$

Uma vez que se busca analisar os ciclos político-orçamentários dos municípios brasileiros por meio da razão entre gastos com investimento e gastos com pessoal, torna-se necessário compilar dados a respeito do desempenho fiscal dos 5570 municípios nas rubricas relacionadas. Para tanto, delimitou-se o período de 1997 a 2017 como foco do estudo, compreendendo, portanto, os quatro mandatos municipais transcorridos integralmente após a estabilização monetária trazida pelo Plano Real (1997-2000; 2001-2004; 2005-2008; 2009-2012 e 20132016). Nesses 20 anos analisados, foram realizadas eleições municipais em 2000 , 2004, 2008, 2012 e 2016. Além disso, ocorreram eleições estaduais e federais em 1998, 2002, 2006, 2010 e 2014. Os dados utilizados são provenientes principalmente da Secretaria do Tesouro Nacional e do Instituto Brasileiro de Geografia e Estatística (IBGE).

\section{Identificação dos ciclos políticos orçamentários nos municípios brasileiros}

Se o ciclo eleitoral for definido a cada dois anos, cabe observar a diferença que há entre esses anos de aumento de investimento e a forma como eles se distribuem dentro de um mandato eleitoral. Assim, a partir da Tabela 1, nota-se que na média o maior nível de investimentos se dá no segundo ano de um governo

\footnotetext{
${ }^{7}$ Nas contas públicas, as rubricas utilizadas foram as seguintes: em gastos com investimento, considerouse a soma das rubricas "Investimentos" e "Inversões Financeiras", que seriam as despesas com a aquisição de imóveis e bens de capitais já prontos, como um prédio utilizado pelo serviço público e cuja construção se deu anteriormente sem o envolvimento direto do governo; em gastos com pessoal, a rubrica "Pessoal e Encargos Sociais"; e em receita corrente, a rubrica "Receitas Correntes".
} 
municipal, quando ocorrem, na verdade, as eleições a nível federal. No momento das eleições municipais, apesar de também se identificar maiores gastos com investimento, o patamar que o indicador investimento/pessoal alcança é menor do que no $2^{\circ}$ ano. A diferença para esses patamares do indicador entre o $2^{\circ}$ e $4^{\circ}$ ano é da ordem de $17,7 \%$ para todos os municípios. Tal nível mais elevado no $2^{\circ}$ ano é característico de todas as regiões e de todas as faixas populacionais, exceto a de mais de 500 mil habitantes, que investe mais no $4^{\circ}$ ano do que no $2^{\circ}$ ano. Além disso, na região Sul, que também investe mais no $2^{\circ}$ ano, a diferença é menor do que nas demais regiões.

Tabela 1 - Razão investimento/pessoal por ano de mandato municipal

\begin{tabular}{l|c|c|c|c|c}
\hline & $\mathbf{1}^{\mathbf{0}}$ ano & $\mathbf{2}^{\mathbf{o}}$ ano & $\mathbf{3}^{\mathbf{o}}$ ano & $\mathbf{4}^{\mathbf{0}}$ ano & $\begin{array}{c}\text { Razão } \\
\mathbf{2}^{\mathbf{a n o}} \mathbf{\mathbf { 4 } ^ { \mathbf { 0 } }} \text { ano }\end{array}$ \\
\hline Todos os Municípios & 0,255 & 0,359 & 0,270 & 0,305 & 1,177 \\
Por Faixa Populacional & & & & & \\
Até 5.000 hab. & 0,306 & 0,427 & 0,309 & 0,354 & 1,205 \\
De 5.001 a 10.000 hab. & 0,251 & 0,375 & 0,271 & 0,313 & 1,198 \\
De 10.001 a 20.000 hab. & 0,235 & 0,341 & 0,252 & 0,286 & 1,193 \\
De 20.001 a 50.000 hab. & 0,226 & 0,308 & 0,247 & 0,270 & 1,142 \\
De 50.001 a 100.000 hab. & 0,236 & 0,289 & 0,253 & 0,281 & 1,031 \\
De 100.001 a 500.000 hab. & 0,254 & 0,305 & 0,259 & 0,282 & 1,080 \\
Mais de 500.000 hab. & 0,237 & 0,259 & 0,246 & 0,266 & 0,973 \\
Por Região Geográfica & & & & & 1,492 \\
Norte & 0,353 & 0,548 & 0,325 & 0,367 & 1,309 \\
Nordeste & 0,247 & 0,354 & 0,243 & 0,271 & 1,157 \\
Sudeste & 0,235 & 0,332 & 0,256 & 0,287 & 1,258 \\
Centro-Oeste & 0,310 & 0,395 & 0,301 & 0,314 & 1,073 \\
Sul & 0,260 & 0,364 & 0,291 & 0,339 & \\
\hline
\end{tabular}

Fonte: Elaboração própria a partir dos dados do Tesouro Nacional e IBGE.

O maior nível de investimentos em anos de eleição federal é também observado por meio da variação percentual do indicador em relação ao ano imediatamente anterior, que se dá de forma particularmente intensa para o $2^{\circ}$ ano. 
A Tabela 2 mostra que, nos anos eleitorais, a relação investimento/pessoal cresce 26,5\% nos municípios brasileiros. Quando se isolam apenas os anos de eleição federal, tal crescimento alcança 39,8\%, taxa 3,0 vezes maior do que a de crescimento nos anos de eleição municipal, que é da ordem de 13,3\%. Logo, percebe-se que os ciclos político-orçamentários municipais são mais fortes nos anos de eleição federal. Isso ocorre para todas as faixas populacionais e todas as regiões. No entanto, novamente os municípios com mais de 500 mil habitantes e os da região Sul revelam uma peculiaridade: são eles que proporcionalmente menos aumentam os investimentos em anos de eleição federal, indicando uma relativa maior capacidade de investimento em anos de eleição municipal.

\section{Tabela 2 - Crescimento médio do indicador investimento/pessoal nos anos} eleitorais

\begin{tabular}{l|c|c|c|c}
\hline & $\begin{array}{c}\text { Todos os } \\
\text { anos de } \\
\text { eleição }\end{array}$ & $\begin{array}{c}\text { Somente anos } \\
\text { de eleição } \\
\text { federal }\end{array}$ & $\begin{array}{c}\text { Somente anos de } \\
\text { eleição municipal }\end{array}$ & Razão \\
\hline Todos os Municípios & $26,5 \%$ & $39,8 \%$ & $13,3 \%$ & 3,0 \\
Por Faixa Populacional & $27,4 \%$ & $39,9 \%$ & $14,8 \%$ & 2,7 \\
Até 5.000 hab. & $32,2 \%$ & $48,1 \%$ & $16,3 \%$ & 2,9 \\
De 5.001 a 10.000 hab. & $29,0 \%$ & $44,0 \%$ & $14,1 \%$ & 3,1 \\
De 10.001 a 20.000 hab. & $22,5 \%$ & $35,4 \%$ & $9,6 \%$ & 3,7 \\
De 20.001 a 50.000 hab. & $17,2 \%$ & $23,0 \%$ & $11,4 \%$ & 2,0 \\
De 50.001 a 100.000 hab. & $14,5 \%$ & $19,9 \%$ & $9,1 \%$ & 2,2 \\
De 100.001 a 500.000 hab. & $10,5 \%$ & $12,9 \%$ & $8,0 \%$ & 1,6 \\
Mais de 500.000 hab. & & & & \\
Por Região Geográfica & $33,1 \%$ & $53,3 \%$ & $13,0 \%$ & 4,1 \\
Norte & $26,0 \%$ & $39,3 \%$ & $12,7 \%$ & 3,1 \\
Nordeste & $26,9 \%$ & $41,9 \%$ & $11,9 \%$ & 3,5 \\
Sudeste & $16,7 \%$ & $25,4 \%$ & $8,1 \%$ & 3,1 \\
Centro-Oeste & $28,1 \%$ & $39,5 \%$ & $16,7 \%$ & 2,4 \\
Sul & & & & \\
\hline Fon & & & & \\
\hline
\end{tabular}

Fonte: Elaboração própria a partir dos dados do Tesouro Nacional e IBGE. 
A LRF teve um efeito direto no sentido de diminuir o patamar de investimentos nos municípios brasileiros. É isso que mostra a Tabela 3, ao indicar que, na média, o indicador investimento/pessoal decresceu 20,1\% com a promulgação da lei em 2000, que passou a vigorar plenamente em 2001. A diminuição pode ser observada em todas as faixas populacionais e em todas as regiões. Mais uma vez, pode-se destacar o comportamento da região Sul, que diminui proporcionalmente menos o indicador, o que ajuda a explicar o motivo pelo qual essa região se tornou a que mais investe a partir do ano 2008 , conforme já apontado anteriormente.

Tabela 3 - Indicador investimento/pessoal nos períodos pré LRF e pós LRF

\begin{tabular}{lcccc}
\hline & Pré-LRF (1997-2000) & Pós-LRF (2001-2017) & Diferença \\
\hline Todos os Municípios & 0,350 & 0,279 & $-20,1 \%$ \\
Por Faixa Populacional & & & \\
Até 5.000 hab. & 0,408 & 0,330 & $-19,2 \%$ \\
De 5.001 a 10.000 hab. & 0,360 & 0,283 & $-21,5 \%$ \\
De 10.001 a 20.000 hab. & 0,327 & 0,262 & $-19,9 \%$ \\
De 20.001 a 50.000 hab. & 0,306 & 0,248 & $-18,7 \%$ \\
De 50.001 a 100.000 hab. & 0,316 & 0,248 & $-21,5 \%$ \\
De 100.001 a 500.000 hab. & 0,311 & 0,263 & $-15,6 \%$ \\
Mais de 500.000 hab. & 0,299 & 0,236 & $-20,9 \%$ \\
Por Região Geográfica & & & \\
Norte & 0,507 & 0,362 & $-28,6 \%$ \\
Nordeste & 0,378 & 0,246 & $-34,9 \%$ \\
Sudeste & 0,318 & 0,264 & $-16,9 \%$ \\
Centro-Oeste & 0,453 & 0,289 & $-36,0 \%$ \\
Sul & 0,328 & 0,309 & $-5,7 \%$ \\
\hline Fonte Elaboçä0 & & \\
\hline
\end{tabular}

Fonte: Elaboração própria a partir dos dados do Tesouro Nacional e IBGE. 


\section{Conclusões}

O objetivo do artigo foi identificar a existência de ciclos político-eleitorais nos municípios brasileiros e a forma como eles se relacionam com a estrutura federativa adotada pelo país e com a promulgação da Lei de Responsabilidade Fiscal, importante marca institucional de ordenação dos gastos públicos. Para tanto, utilizou-se a base teórica derivada da teoria iniciada com o texto de William D. Nordhaus na década de 70, cujos desenvolvimentos subsequentes levaram ao surgimento de uma discussão focada na relevância da política fiscal expressa por meio de alocações orçamentárias.

Utilizou-se a razão gastos com investimento/gastos com pessoal, que sintetiza tanto a trajetória dos investimentos em relação à receita corrente líquida quanto a dos gastos com pessoal em relação à receita corrente líquida.

A partir das séries históricas que são então construídas, pode-se observar claramente a existência de ciclos político-orçamentários para os municípios brasileiros, o que é derivado principalmente de variações nos investimentos. A situação que se percebe pode ser descrita, assim, como uma em que a maior discricionariedade em relação aos gastos com investimento faz com que eles sejam utilizados de forma oportunista com o objetivo de sinalizar competência justamente em épocas mais convenientes, que seriam as épocas de eleição. No entanto, mesmo a LRF não impondo regras para as despesas com investimentos, eles estão sujeitos a uma restrição devido ao limite para as operações de crédito. Ou seja, de forma a não se estourar os limites de endividamento, cortam-se na sequência os investimentos, algo que é possível devido a menor rigidez desses gastos. Esse uso eleitoral dos investimentos pode acarretar problemas variados: investimentos iniciados em anos de eleições e paralisados na sequência, uso não eficiente dos recursos públicos, discricionariedade visando atingir objetivos políticos e não necessariamente de melhor alocação orçamentária etc.

Assim, o impacto da LRF em relação aos ciclos não aparenta ser positivo: não só eles foram canalizados para os gastos com investimentos como também não se identifica uma diminuição do percentual de crescimento dessas despesas em anos eleitorais. Os ciclos, portanto, mostram-se resilientes quando observados a partir de indicadores de investimento. O que se identifica de diferente, na verdade, é apenas uma redução do patamar a partir do qual os ciclos ocorrem, com uma diminuição dos investimentos, os quais foram cortados devido à necessidade de 
ajustes fiscais no período pós-LRF. Dito de outra forma, na média se investe menos após a LRF e os ciclos se mantiveram iguais.

Além disso, uma análise por faixa populacional e região geográfica dos municípios permite tirar algumas conclusões adicionais. Primeiramente, os ciclos mais fortes ocorrem em anos de eleição federal nos municípios menores e naqueles da região Nordeste. Esses dois grupos são justamente os que mais dependem de recursos federais, indicando que as transferências governamentais podem estar sendo utilizadas de forma a propiciar maiores repasses para os municípios dependentes nas épocas de eleição - isso com o objetivo de criar um cenário positivo que traga lucros eleitorais. Comparativamente, os municípios maiores e os da região Sul não possuem essa situação tão bem definida. Neles, por haver uma menor dependência por recursos de transferências, os ciclos não são tão fortes nas eleições federais e a variação é relativamente maior em anos de eleição municipal, apontando para a maior autonomia que esses municípios possuem para definirem seus gastos. Observa-se, ainda, um maior nível de investimentos na região Sul nos anos mais recentes da amostra. Apesar de, em todas as demais regiões, os investimentos pós LRF terem diminuído sensivelmente, isso não ocorreu na mesma magnitude nos municípios sulistas. Isso pode ser reflexo de cenário fiscal mais favorável já antes da promulgação da lei, o que minorou a necessidade de implantação de um ajuste fiscal significativo e voltado para os investimentos.

\section{Referências}

DRAZEN, A. The Political Business Cycle after 25 Years. In: BERNANKE, B.S.; ROGOFF, K. (Ed.). NBER Macroeconomics Annual 2000 - Volume 15. Cambridge: MIT Press, 2001.

DRAZEN, A.; ESLAVA, M. Electoral Manipulation via Expenditure Composition: theory and Evidence. Cambridge: National Bureau of Economic Research, 2005.

FIALHO, T. M. M. Ciclos Políticos: uma Resenha. Revista de Economia Política, v. 19, n. 2, p. 131-149, 1999.

KLEIN, F. A.; SAKURAI, S. N. Term limits and political budget cycles at the local level: evidence from a young democracy. European Journal of Political Economy, v. 37, p. 21-36, 2015. 
MENEGUIN, F. B.; BUGARIN, M. S. Reeleição e Política Fiscal: Um Estudo dos Efeitos da Reeleição nos Gastos Públicos. Economia Aplicada, v. 5, n. 3, p. 600$622,2001$.

NAKAGUMA, M. Y.; BENDER, S. Mudança Institucional e Política Fiscal no Brasil: uma avaliação da experiência recente. Brasília: ESAF, 2005. 80 p. X Prêmio Tesouro Nacional - 2005, Lei de Responsabilidade Fiscal, Brasília (DF).

NORDHAUS, W. D. The Political Business Cycle. Review of Economic Studies, n. 42, n. 2, p. 169-190, 1975.

ROGOFF, K.; SIBERT, A. Elections and macroeconomic policy cycles. Review of Economic Studies, n. 55, n. 1, p. 1-16, 1988.

SAKURAI, S. N.; MENEZES-FILHO, N. A. Fiscal policy and reelection in Brazilian municipalities. Insper Working Paper 124. São Paulo: IBMEC, 2008

SHI, M.; SVENSSON, J. Political Budget Cycles: A Review of Recent Developments. Nordic Journal of Political Economy, v. 29, n. 1, p. 67-76, 2003.

VEIGA, L. G.; VEIGA, F. J. Political Business Cycle at the Municipal Level. Public Choice, v. 131, n. 1/2, p. 45-64, 2007. 